\title{
Effects of Dry Sliding Wear of Wrought Al-Alloys on Mechanical Mixed Layers (MML)
}

\author{
Mariyam Jameelah Ghazali \\ Department of Mechanical \& Materials Engineering \\ Universiti Kebangsaan Malaysia \\ Malaysia
}

\section{Introduction}

Aluminium alloys are very attractive compared to other materials like steels, particularly for their mechanical properties. Despite of having a relatively low density $\left(2.7 \mathrm{~g} / \mathrm{cm}^{3}\right.$ as compared to $\pm 7.9 \mathrm{~g} / \mathrm{cm}^{3}$ of steel), they also possess high ductility (even at room temperature), high electrical and thermal conductivity and resistance to corrosion and high thermal conductivity. However, aluminium by itself exhibits poor tribological properties and their usage, for example in automotive applications, has been limited by their inferior strength, rigidity and wear resistance, compared with ferrous alloys. With respect to friction and wear behaviour, it has been well understood that the tribological behaviour of aluminium alloys is strongly influenced by the mechanical, physical and chemical properties of the near-surface materials. Whether lubricated or dry sliding, there is evidence that substantial work-hardening occurs at the worn surface. Surface strains can be well in excess of those found in conventional mechanical working. Intimate contact between ductile materials in particular, normally involved transferred materials, which may result in the formation of a mechanically mixed layer (MML). The MML was generally found to be comprised of materials from both contact surfaces, and may also include oxygen, and was known to have very different properties to the Al-alloy. Although the formation of an MML was known to modify wear behaviour, the exact manner was not fully understood. Moreover, very little was known about the effect that matrix alloy composition had on MML formation although it was claimed that the MML could improved wear resistance.

\section{Backgrounds}

\subsection{Sliding wear theory}

Wherever surfaces move against each other, wear will occur; damage to one or both surfaces generally involves progressive loss of material (ASM International \& 1992 Hutchings, 1992). The rate of removal is generally slow. Although the loss of material is relatively small, it can be enough to cause complete failure of large and complex machinery. Hence, it is essential to develop a thorough understanding of the wear process, especially its mechanism and behaviour, in order to optimise performance. In the current work, only dry or unlubricated sliding wear will be further discussed, even though it is often associated with an environment containing appreciable humidity. When two surfaces slide or roll against each other under an applied load, two forces will exist: 
1. The load acts normal to the surface areas that in contact will exert a compressive stress on the materials, which has a similarity with cold working and is usually concentrated in the rolling case.

2. A force exerted by the machine in the direction of motion, overcomes the following resistance:

- The friction force, $\mathrm{F}$, that is proportional to the normal load between contacting surfaces.

- The static coefficient of friction, that is higher at the start of the motion than the dynamic friction.

- Adhesion; the tendency of the two mating metals to adhere to each other. It may result in the surfaces being locally bonded together, forming a junction.

- In extreme cases, resistance to motion is caused by abrasive material.

\subsection{Wear of aluminium alloys}

Due to their low density and excellent corrosion resistance, aluminium has become a substitute for steels especially in structures that require high performance and weight reduction. As with most other metals, aluminium reacts with oxygen in air. A submicron thick oxide layer is formed to provide effective corrosion protection. Aluminium is also nonmagnetic and non-toxic, and can be formed by all known metal working processes. The density of aluminium is $2.7 \mathrm{~g} / \mathrm{cm}^{3}$ or approximately one third the density of steel and aluminium alloys have tensile strengths of between 70 and $700 \mathrm{~N} / \mathrm{mm}^{2}$. At low temperatures the strength of aluminium and its alloys increases without embrittlement in contrast to most steels (Pollack, 1977). Table 1 shows a comparison of the physical characteristics of some of the most important construction materials.

During the 1980 's, about $85 \%$ of aluminium was used in the wrought form, that is rolled to sheet, strip or plate, drawn to wire or extruded as rods or tubes (Higgins, 1987 and Polmear, 1989). Some of the alloys may undergo subsequent heat-treatment in order to achieve the desired mechanical properties. The most common methods to increase the strength of aluminium alloys are:

- $\quad$ To disperse any second-phase constituents or elements in solid solution and cold work the alloy; there are known as non-heat-treatable alloys.

- To dissolve the alloying elements in solid solution and re-precipitate them. These are also as heat-treatable or precipitation-hardening alloys (originally known as 'agehardening' alloys).

\begin{tabular}{|l|c|c|c|c|}
\hline & $\mathrm{Al}$ & $\mathrm{Fe}$ & $\mathrm{Cu}$ & $\mathrm{Zn}$ \\
\hline Density $\left(\mathrm{g} / \mathrm{cm}^{3}\right)$ & 2.7 & 7.9 & 8.9 & 7.1 \\
\hline Melting Point $(\mathrm{YP})\left({ }^{\circ} \mathrm{C}\right)$ & 660 & 1540 & 1083 & 419 \\
\hline Electrical conductivity $(\%)$ & 63 & 16 & 100 & 30 \\
\hline Specific Heat/Thermal Volume $(\mathrm{J} / \mathrm{kg}, \mathrm{K})$ & 900 & 450 & 390 & 390 \\
\hline Thermal Conductivity $(\mathrm{W} / \mathrm{m}, \mathrm{K})$ & 220 & 75 & 390 & 110 \\
\hline Linear exp. coefficient $\left(10^{-6} / \mathrm{K}\right)$ & 24 & 12 & 16 & 26 \\
\hline Electrical resistance $\left(10^{-9} \mathrm{ohms} / \mathrm{m}\right)$ & 27.5 & 105 & 17 & 58 \\
\hline Young's Modulus, $(\mathrm{GPa})$ & 70 & 220 & 120 & 93 \\
\hline
\end{tabular}

Table 1. Physical characteristics of some of the most important construction materials 
Two major and most common types of wear identified by Eyre (1979) that are relevant to industrial applications of aluminium alloys are abrasive and sliding wear especially for $\mathrm{Al}-\mathrm{Si}$ alloys. In the case of $\mathrm{Al}-\mathrm{Si}$, generally, the hard silicon particles addition will contribute to higher hardness hence increase the wear resistance. Moreover, the particles are surrounded by softer and relatively tough matrix, which then improves the overall toughness of the material. This will lead to wear resistance by favouring more plastic behaviour (ASM Handbook, 1994).

As for aluminum alloys that reinforced with ceramic particles, they have shown significant improvements in mechanical and tribological properties including sliding and abrasive wear resistance (Rittner, 2000). The hard ceramic particles provide protection from further detrimental surface damage. An increase of ceramic hard particles content in alloys may enhance its wear resistance behaviour (Geng et al., 2009). The ageing behaviour of discontinuous reinforced metal matrix composites has been a subject of great interest, which is beneficial to optimise the ageing treatment and providing the experimental and theoretical information for designing the composites properties (Sheu and Lin, 1997). Aluminum nitride $(\mathrm{AlN})$ as a reinforcement material has received much interest in electronic industry because of the need for smaller and more reliable integrated circuit.

For applications, aluminium based alloys have been widely used, for instance Al-Sn alloys as bearing metals in automobile designs. The most important properties of being a bearing metal are that it should be hard and wear-resistant, and have a low coefficient of friction. At the same time, it must be tough, shock-resistant, and sufficiently ductile to allow for running-in ${ }^{1}$ processes made necessary by slight misalignments.

\section{Mechanically Mixed Layers (MML)}

\subsection{Formation of the MML}

In the case of ductile materials like aluminium alloys, most wear mechanism observed are consistent with Archard adhesive wear characterised by plastic ploughing and transfer of material from the counterface. With respect to friction and wear behaviour, numerous authors (Perrin and Rainforth, 1995, Leonard et al., 1997, Jiang and Tan, 1996, How and Baker, 1997 and Rigney, 1998) have concluded that the tribological behaviour is influenced by the mechanical, physical and chemical properties of these near-surface materials. In all cases, a mechanically mixed layer (MML) was present in most dry worn wrought aluminium alloys due to the repetitive sliding. However, significant differences between the MML of each alloy were observed. Their thickness which varied with loads suggested that the subsurface zones of the materials to the sliding and impact wear consisted of 3 zones (Rice et al., 1981) as indicated in Fig. 1.

a. Zones 1 - represents the undisturbed base material or original specimen material in the undeformed state, which experiences elastic deformation and thermal cycling when loaded in tribocontact. Its structure and properties are identical to those prior to the wear test.

b. Zones 2 - consists of the part of the original specimen that has obtained new properties due to repetitive tribocontact. Basically, sufferred deformed intermediate region of the base material. Here, plastic deformation occurs especially in ductile materials, grains are distorted and cracks or voids may nucleate.

\footnotetext{
1 The process by which machine parts improve in conformity, surface topography and frictional compatibility during the initial stage of use.
} 
c. Zones 3 - is known as tribolayer which forms in-situ, and usually contains chemical species from the counterface and test environment as well as the bulk material.

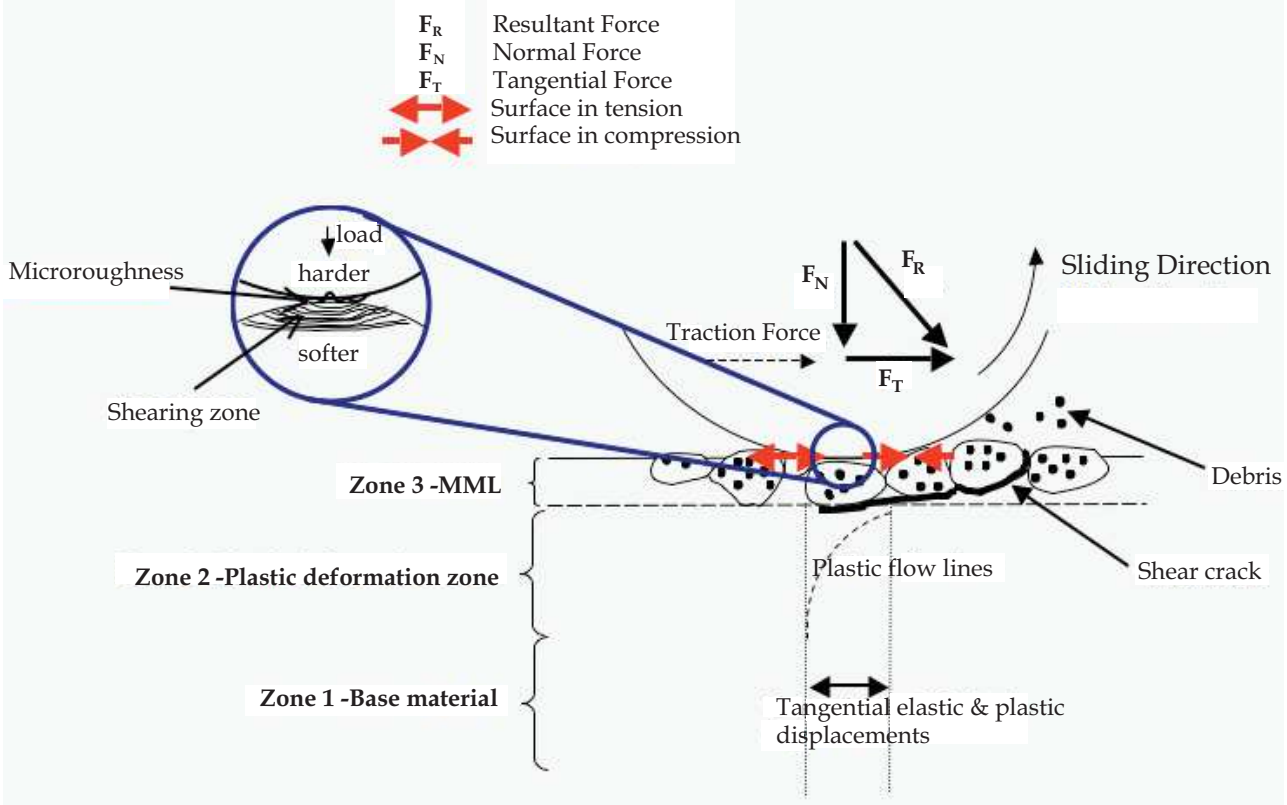

Fig. 1. An illustration of deformation during dry sliding (Ghazali, 2005)

The mixed layer (zone 3), which is commonly known as the mechanically mixed layer (MML), was formed through the incidental mixing between the two materials that statistically occurs at the contact spots under normal pressures. Crack and void formation were generally associated at the zone $2 / 3$ interface and may dictate the dimensions of the wear debris formed (Suh, 1973). The extent and compositional features of these sub-surface zones were found to depend on the conditions of sliding wear, material and environment. Rice et al. (1981-1982) also indicated that these sub-surface zones developed quickly under dry sliding wear conditions. The present work has confirmed that a MML was formed in the sliding wear of the Al-alloys against both counterfaces. Its particles are recognised to have the same physical structure and chemical composition as those of the base pair (Biswas, 2000). The distinctive morphology of the mixed layer has led to a suggestion that its formation was due to a compression of the transfer material and the entrapped debris, which was followed by mechanical mixing during the sliding process. As highlighted by Heilmann et al. (1983), the MML which develops at an early stage (even before loose debris was obtained), is common in both dry and lubricated sliding wear process. In dry sliding condition, a high compressive pressure and large shear strains in the asperities were produced. Heavy plastic deformation and shear strains in the worn surface give rise to dislocation cells and elongated subgrains, as seen in i.e; Fig. 2, which is consistent with Heilmann et al. (1983), Rigney et al. (1981), Chen (1986), Chen and Rigney (1986) and Kuo and Rigney (1992). 

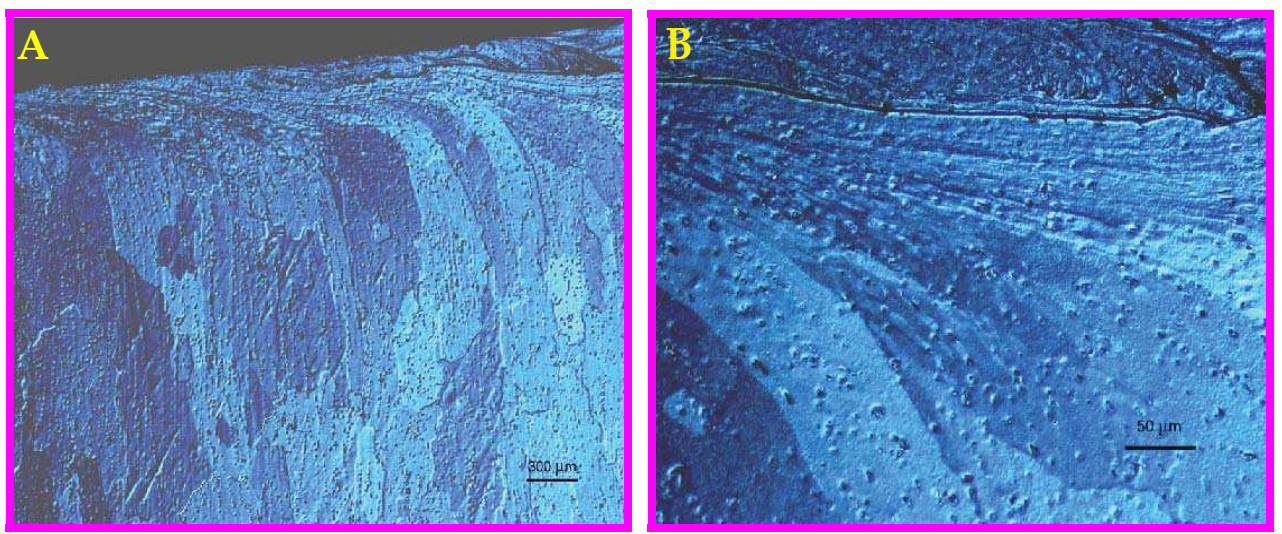

Fig. 2. A is an example of A3004 alloys after $10.8 \mathrm{~km}$ slid against M2 at $140 \mathrm{~N}$. B is the magnified (Normaski) view of a selected area (Ghazali, 2005)

Some MML was very thin and the matrix of the $\mathrm{Al}$ alloy almost approached to the top worn surface, is very likely associated with the plastic flow during deformation, where the mixed layer can be replenished with fresh base material by a large plastic flow in the subsurface (Li and Tandon, 1999). Biswas (2000) studied the thickness of the MML appears to be controlled by the depth of crater and abrasion grooves made on the surface. In fact, he further concluded that one of the pre-requisites for the formation of this MML correlates with severe deformation of the top layer of the softer material pair, which in this case is the aluminium alloys. It appears that, when one surface is softer than the other, metal may be transferred from the soft to the hard surface. The material could be transferred back and forth several times during sliding and eventually produce wear debris particles (Heilmann et al., 1983).

\subsection{Composition of the MML}

In agreement with Rice et al. (1981), Heilmann et al. (1983) and Rigney et al. (1984), the mixed layer is composed of a mixture of two mating materials and from this layer, the loose debris were derived. Based on the results of EDS (Figs. 3), the layer had similar structure and composition to the loose debris. Here, presumably some of the wear debris from the counterface, together with the debris from the pin may have been compacted to form the MML. In other words, it can be concluded that such debris are not derived directly from the base material, with an exception for the case of abrasion, in which microcutting and microploughing are prominent.

In the present study, the MML were found to contain $\mathrm{Al}$, Fe (for $\mathrm{Al} / \mathrm{M} 2$ case) and $\mathrm{O}$ (in the form of oxide), which proves the source of element in the MML obviously originated from the counterface. The oxides were found to be coexisted with other phases in the MML and the wear debris, which is an expected phenomenon since the wear system was exposed to air. They could provide microstructural stability as a second phase in the ultrafine grained structure in debris, as proposed by Rigney et al. (1984). The oxides which have been known to form some protective and some destructive (Fischer, 1997 and Ravikiran et al., 1995) were then fractured and comminuted in further sliding process. The crushed oxides can be 
dispersed into the mixed surface layer and act as a pinning source of the grain boundaries in the ultrafine mixture in the MML and in the wear debris (Li and Tandon, 1999).

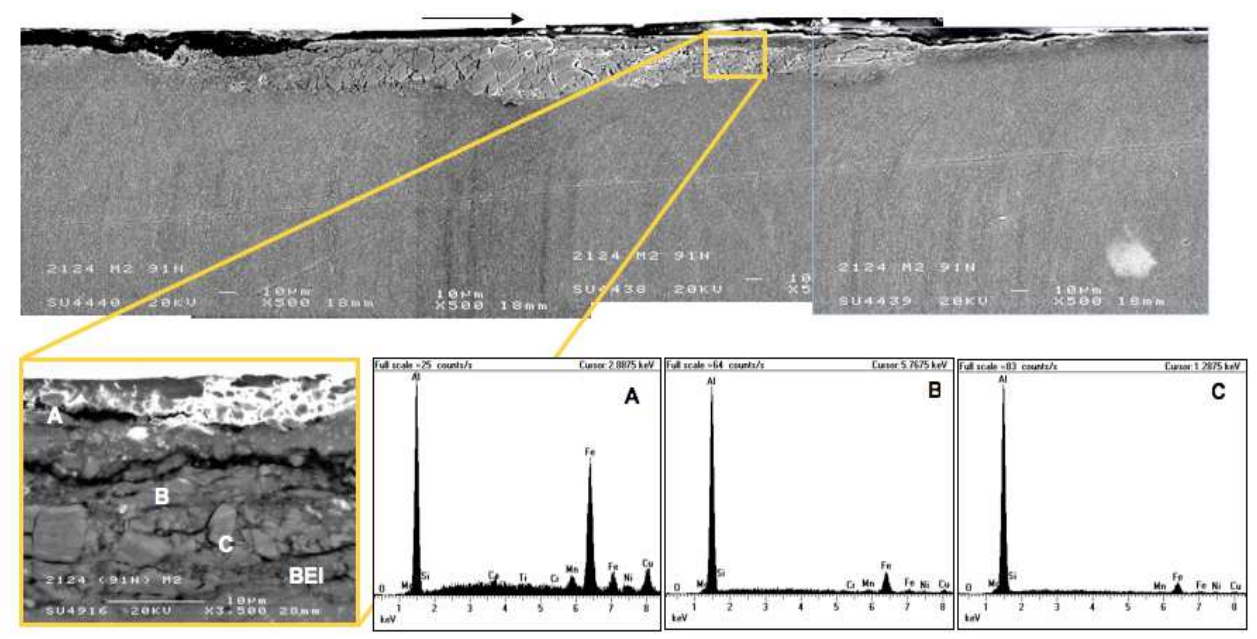

Fig. 3. Subsurface damage of longitudinal cross sections of A2124 alloys against M2 at 140N after sliding $10.8 \mathrm{~km}$. Black arrows indicate the direction of sliding. A corresponding EDS analysis are shown in A, B and C areas (Ghazali, 2005)

\subsection{The correlation between the MML and the wear debris}

As for wear debris, its formation appeared to occur by two principal mechanisms, namely, the physical displacement of material from the worn surface by the ploughing action of the hard tool steel or alumina asperities, and secondly, delamination of large sheets (up to $1 \mathrm{~mm}$ in extent) at particularly at high load like $140 \mathrm{~N}$. The thickness of the delamination sheets was found broadly consistent with the thickness of the MML, although it could not be defined with certainty whether the delamination occurred within the MML or at the MML/substrate interface. However, the longitudinal cross-sections suggested that both mechanisms were probable. Moreover, the cracks in the MML can give rise to delamination wear as a result of subsurface shear in a manner proposed by Suh (1977) where plate-like wear debris is produced. As one of the main principal wear mechanism in the present study was the delamination of the MML (part or whole), it would be reasonable to expect a correlation between MML thickness and specific wear rate.

\subsection{The correlation between MML thickness and specific wear rate}

A detailed comparison between several commercial wrought aluminium alloys, namely; A2124, A3004, A5056 and A6092 was carried out for this purpose. For this Al/M2 system, the specific wear rate was relatively insensitive to MML thickness for the A3004 and A5056, although the specific wear rate decreased in a linear manner with increasing MML thickness (refer to Fig. 4a).

In contrast, for the A2124 and particularly the A6092, the specific wear rate was a strong function of the MML thickness. Although a reasonable linear fit was possible for the A2124, 


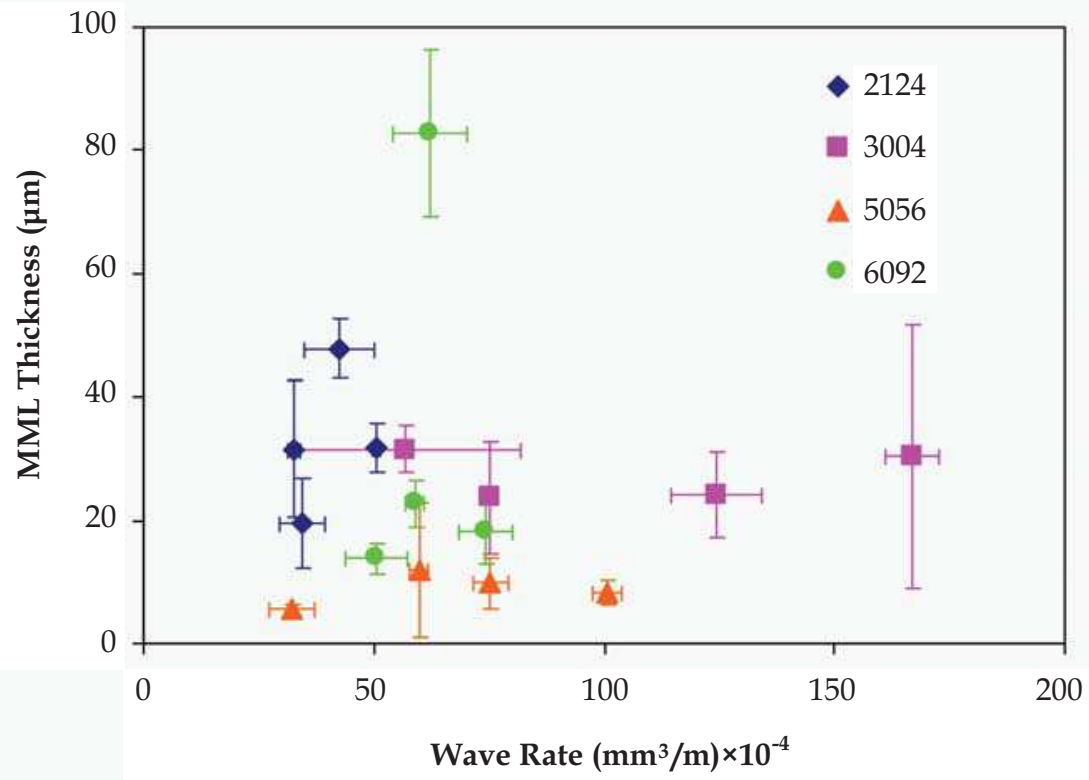

(a)

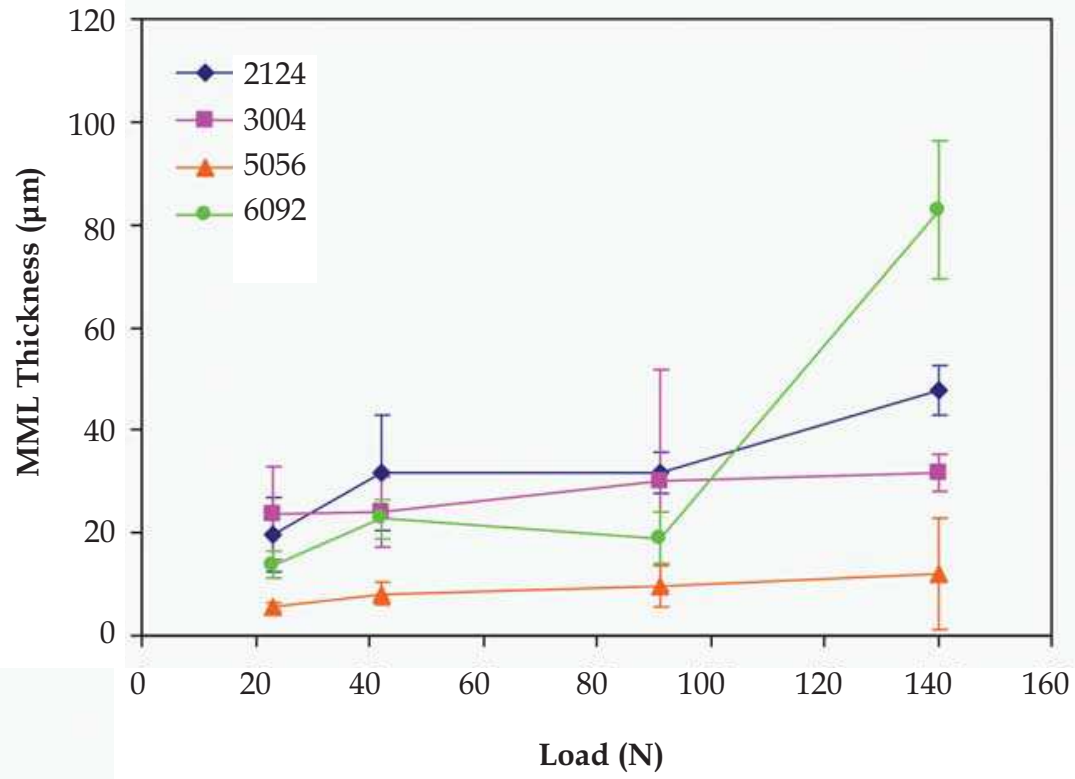

(b)

Fig. 4. The relationship between MML thickness and (a) wear rate and (b) load after $10.8 \mathrm{~km}$ against M2 counterface (Ghazali, 2005) 
the A6092 data was better represented by an exponential fit. Since this data did not fit the same trend as the other alloys, the experiment was repeated and measurements re-taken, but with essentially the same result. Thus, the difference in behaviour of this alloy appears to be reproducible. Interestingly, the two alloys where the specific wear rate was relatively insensitive to MML thickness also exhibited MML with the least Fe content (Table 2) and the most homogeneous structure. Conversely, the A6092 exhibited the highest Fe content, the most heterogeneous structure and the greatest influence on the specific wear rate. However, the thickness of the MML cannot explain the dramatic drop in specific wear rate with load observed for the A3004 alloy (Fig. 4b). The thickness of the MML is only one of several potential ways in which the MML can affect wear rate. Clearly for Al/M2 system, the mechanical properties of the MML (in particular hardness and fracture stress) and its adhesion to the substrate are contributing factors.

\begin{tabular}{|c|c|c|c|c|c|c|c|c|}
\hline \multirow{2}{*}{ Element } & \multicolumn{2}{|c|}{2124} & \multicolumn{2}{c|}{3004} & \multicolumn{2}{c|}{5056} & \multicolumn{2}{c|}{6092} \\
\cline { 2 - 9 } & $\mathbf{4 2 N}$ & $\mathbf{1 4 0 N}$ & $\mathbf{2 3 N}$ & $\mathbf{1 4 0 N}$ & $\mathbf{2 3 N}$ & $\mathbf{1 4 0 N}$ & $\mathbf{4 2 N}$ & $\mathbf{1 4 0 N}$ \\
\hline$M g$ & $1.8 \pm 0.3$ & $2.0 \pm 0.4$ & - & - & $6.8 \pm 0.5$ & $6.8 \pm 1.1$ & $1.0 \pm 0.1$ & $1.7 \pm 0.3$ \\
\hline$A l$ & $85.3 \pm 1.9$ & $73.4 \pm 5.9$ & $94.9 \pm 9.2$ & $95.3 \pm 5.6$ & $80.5 \pm 7.8$ & $86.8 \pm 7.7$ & $61.8 \pm 7.6$ & $79.9 \pm 5.8$ \\
\hline$S i$ & $1.0 \pm 0.5$ & - & $0.7 \pm 0.2$ & $0.8 \pm 0.3$ & $1.0 \pm 0.4$ & $0.4 \pm 0.1$ & $1.6 \pm 0.4$ & $1.1 \pm 0.3$ \\
\hline$M n$ & $1.1 \pm 0.1$ & $1.4 \pm 0.5$ & $2.5 \pm 1.8$ & $1.1 \pm 0.2$ & - & - & $0.3 \pm 0.1$ & - \\
\hline$F e$ & $6.6 \pm 1.5$ & $19.1 \pm 4.8$ & $1.9 \pm 1.5$ & $2.7 \pm 1.8$ & $11.7 \pm 5.4$ & $6.0 \pm 5.5$ & $34.5 \pm 7.8$ & $15.9 \pm 7.4$ \\
\hline$C u$ & $4.3 \pm 0.6$ & $4.1 \pm 1.1$ & - & - & - & - & $0.8 \pm 0.2$ & $1.3 \pm 0.6$ \\
\hline
\end{tabular}

Table 2. Average quantitative EDS analysis on MML of Al-alloys against M2 (Ghazali, 2005)

In Al/M2 system, the A6092 exhibited the thickest MML and the highest Fe content. Since this was not replicated by the A5056, rather the reverse, it is clear that it is not the $\mathrm{Mg}$ content of the A6092 that promotes the formation of a thick MML. Thus, these results imply that stronger adhesion and transfer from the counterface is promoted by the $\mathrm{Si}$ in the alloy, while a high $\mathrm{Mg}$ content in the Al-alloy reduces adhesion. Similarly, the presence of $\mathrm{Cu}$ in the A2124 also appears to have promoted stronger adhesion than an equivalent amount of $\mathrm{Mg}$, although the $\mathrm{Cu}$ was not as potent as the $\mathrm{Si}$. The $\mathrm{Mn}$ in the A3004 also promoted a relatively thick MML, but one that was more homogeneous than for the A6092. The solubility of these elements in $\alpha-\mathrm{Al}$ is in the order $\mathrm{Si}, \mathrm{Mn}, \mathrm{Cu}, \mathrm{Mg}$, which roughly approximates to the thickness of the MML formed. Thus, the observations are in-line with the Archard theory of adhesive wear, as might be expected. However, the level of alloy additions are small (e.g. Si) and it is surprising that the effect was as strong as observed. Thus, the wear performance is largely determined by the properties of the MML.

\subsection{Effect of other variables}

The atmosphere under an unlubricated wear process can strongly influence sliding wear rates with oxygen content and humidity being probably one of the important factors. In the 
case of Al-alloys, it is readily combined with oxygen to form a stable oxide layer. Oxidation, may have opposing effects on the wear process; one, it degraded the surface by removing metal atoms and second, it plays protective role in reducing metallic contact and decrease the wear rate (Degnan, 1995). However, whether or not the environment reaction has a beneficial and detrimental effect on wear rate, it depends strongly on the mechanical interaction of the reaction product with the substrate, particularly under surface plasticity condition, (Rainforth et al., 2002), which is in line with the present work.

Moisture in the environment also can have major effect on wear of metals. Endo and Goto (1978) reported the high humidity had a dentrimental effect on the fretting of aluminium alloys but negligible on carbon steels. Moreover, humidity can control the friction at room temperatures, particularly ceramics as higher coefficient of friction may occurr at temperatures above $800^{\circ} \mathrm{C}$.

Beside humidity, all wear processes are influenced by temperature. The temperature reached at the surface of the contact is strongly influenced by the width of the contact (Johnson, 1985) and flash temperature is responsible for many wear and friction effects (Gecim and Winer, 1986). Wear occurs in conjunction with the dissipation of frictional energy in the contact and this is always accompanied by a rise in temperature. The frictional energy is generated by the combination of load and sliding speed and its distribution and dissipation is influenced by other contact conditions such as size and relative velocity. In regards to temperature effects on sample size and mass, contact spots have a tendency to remain in one place much longer on the smaller pin (alloy) than the larger side (counterface), causing stronger local heating in the former. Moreover, in this work, the rotating counterface will mostly experience extra cooling convention than the stationary alloy, which constantly hot due to repeated passage during the test. Local heating at contact spots also has other effect. Most obviously, the local hardness is reduced and thereby the load-bearing area is increased (Kuhlmann-Wilsdorf, 1987).

At high loads like the one used in the present study, $140 \mathrm{~N}$, friction heating can induce an increase in temperature, resulting a thermal softening beneath the worn surface, and may affect the wear mechanism (Zhang and Alpas, 1997 and Wang and Rack 1991). Maupin et al., $(1992,1993)$ studied that large grains were replaced by fine nanocrystalline grains which were relatively free of dislocations underneath the worn surface. Such microstructures could develop only if the temperature of the surface due to friction is very high. In addition, the deformed layer beneath the worn surface could result in higher plastic flow and work hardening resulting in increased wear resistance. At such high temperature, oxidation of the surface is also a possibility, as observed in earlier results.

\section{Conclusion}

In general, the dry sliding of $\mathrm{Al} / \mathrm{M} 2$ systems showed the following responses as a result of repeated stress and frictional heat cycle:

- Elements present in the Al-alloy with high solubility in steel promoted a thick mechanically mixed layer, with higher Fe content. The effect was marked even for small contents in the Al-alloy.

- $\quad$ The solubility of these elements in $\alpha$-Fe is in the order of $\mathrm{Si}, \mathrm{Mn}, \mathrm{Cu}, \mathrm{Mg}$, which roughly approximates the thickness of the MML formed. 
- MML with high Fe content tended to be comprised of fragmented particulate, while a low Fe content tended to be associated with a more homogenous MML.

- A linear relationship between specific wear rate and the thickness of the MML was observed for 2124, 5056 and 3004, but not for 6092. The specific wear rate was relatively insensitive to MML thickness for the 3004 and 5056. In contrast, for the 2124 and particularly for the 6092, the specific wear rate was a strong function of the MML thickness.

\section{Acknowledgment}

The financial support of this research through JPA/SLAB (UKM) program, under the guidance of Professor William Mark Rainforth from University of Sheffield is gratefully acknowledged.

\section{References}

ASM Handbook Volume 18 (1992), Friction, Lubrication, and Wear Technology (ASM International).

ASM Specialty Handbook (1993): Aluminium and Aluminium Alloys, edited by Davis, J.R., ASM International, ISBN 978-0-87170-496- 2, Materials Park, OH.

Biswas, S.K. (2000). Some mechanisms of tribofilm formation in metal/metal and ceramic/metal sliding interactions. Wear, Vol. 245, No. 1, pp. 178-189.

Chen, L.H. (1986). Deformation, Transfer and Debris for Mation During Sliding Wear of Metals. Scripta Metall., Vol.24, pp.827-83.

Chen L.H., and Rigney, D. A. (1986). Transfer during unlubricated sliding wear of selected metal system. Wear, Vol. 105, pp. 47-61

Degnan, C.C. (1995). The processing and wear behaviour of a W(TiC) reinforced steel matrix composite, PhD Thesis, University of. Nottingham, Nottingham,

Endo K. and Goto H. (1978). Effects of environment on fretting fatigue. Wear, Vol. 48, No. 2, pp. 347-367.

Eyre, T.S. (1979), Treatise on Materials Science and Tech., edited by Scott, D., Academic Press, New York.

Fischer, T.S. (1997). New Directions in Tribology, edited by Hutchings, MEP Ltd, London.

Gecim, B., and Winer, W.O. (1986). Effect of surface film on the surface temperature of a rotating cylinder. ASME J. Tribol., Vol. 108, pp. 92-97.

Geng, L. Zhang, B.P. Li, A.B. Dong, C.C. (2009). Materials Letters 63 pp. 557.

Ghazali, M.J. (2005), Dry Sliding Wear Behaviour of Several Wrought Aluminium Alloys, PhD. Thesis. University of Sheffield.

Heilman, P., Don, J., Suh, T.C., and Rigney, D.A. (1983). Sliding wear and transfer. Wear, Vol. 91, pp. 171-190.

Higgins, R.A. (1987). Materials for the Engineering Technician, 2nd Ed. Edward Arnold, London.

Hutchings, I.M. (1992). Tribology-Friction and Wear of Engineering Materials, $1^{\text {st }}$ edn., Edward Arnold, ISBN 0-340-56184-x, London, UK. 
How, H.C., and Baker, T.N. (1997). Dry sliding wear behaviour of Saffil-reinforced AA6061 composites. Wear, Vol. 210, pp. 263-272.

Jiang, J.Q., and Tan, R.S. (1996). Dry sliding wear of an alumina short fibre reinforced Al-Si alloy against steel. Wear, Vol. 195, No. 1-2, pp. 106-111.

Johnson, K.L. (1985). Contact Mechanics, Cambridge University Press, Cambridge.

Kuhlmann-Wilsdorf, D. (1987). Demystifying flash temperatures I. Analytical expressions based on a simple model. Mat. Sci. Eng., Vol. 93, pp. 107-118.

Kuo, S.M., and Rigney, D.A. (1992). Sliding Behavior of Aluminum. Mat. Sci. Tech., Vol. 157, pp. 131-143.

Leonard, A.J., Perrin, C., and Rainforth, W.M. (1997). Microstructural changes induced by dry sliding wear of a A357/SiC metal matrix composite. Mater. Sci. Tech., Vol. 13, No. 1, pp. 41-48.

Li, X.Y., and Tandon, K.N. (1999). Mechanical mixing induced by sliding wear of an Al Si alloy against M2 steel. Wear, Vol. 225-229, pp. 640-648

Maupin H.E., Wilson R.D., Hawk J.A. An abrasive wear study of ordered Fe3Al. Wear, Vol. 159, pp. 241-247.

Maupin, H. E. Wilson, R. D. and Hawk, J. A. (1993). Wear deformation of ordered Fe-Al intermetallic alloys. Wear, Vol. 162-164, pp. 432-440.

Perrin, C. and Rainforth, W.M. (1995). The effect of alumina fibre reinforcement on the wear of an Al-4.3\%Cu alloy. Wear, Vol. 181-183, No. 12, pp. 312-324.

Pollack, H.W. (1977). Mat. Sci. and Met., 2nd edn., Virginia, Prentice Hall.

Polmear, I.J. (1989). Metallurgy of the Light Metals, $2^{\text {nd }}$ edn., Edward Arnold. New York.

Rainforth, W.M., Leonard, A.J., Perrin, C., Bedolla-Jacuinde, A.,. Wang, Y., Jones, H., Luo, Q. (2002). High-resolution observations of friction-induced oxide and its Interaction with the Worn Surface. Tribol. Int., Vol. 35, pp. 731-748.

Ravikiran, A., Nagarajan, V.S., and Biswas, S.K., Pramila Bai, B.N. (1995). Effect of. Speed and Pressure on Dry Sliding Interactions of Alumina against Steel. J. Am. Ceram. Soc., Vol. 78, No. 2, pp. 356-364.

Rice S.L., Nowothy, H., and Wayne, S.F. (1981-1982). Characteristics of metallic subsurface zones in sliding and impact wear. Wear, Vol. 74, pp. 131 -142

Rigney, D.A., ed. 1981, in Fundamentals of Friction and Wear of Materials: Am. Soc. for Metals, Metals Park, Ohio.

Rigney, D.A., Chen, L.H., Naylor, M.G., and Rosenfield, A. (1984). Wear processes in sliding systems. Wear, Vol. 100, pp. 195-219.

Rigney, D.A. (1998). Large Strains Associated with Sliding Contact of. Metals. Mater. Res. Innovat., Vol. 1, pp 231-234.

Rittner, M. (2000). Metal matrix composites in 21st. century: markets and opportunities, BCC, Inc., Norwalk, C.T.

Sheu, C.Y. Lin, S.J. (1997). Journal of materials science, 32 pp. 1741.

Suh, N.P. (1973). The delamination theory of wear. Wear, Vol. 25, pp. 111-124.

Suh N.P., Jahanmir, S., Flemming, J.R., Pamies-Teixeira, J.J., Saka, N. (1977). Overview of the Delamination Theory of Wear. Wear, pp. 44, 1-16.

Wang A., Rack H.J. (1991). Abrasive wear of silicon carbide particulate-and whiskerreinforced 7091 aluminum matrix composites. Wear, Vol. 146, pp. 337-348. 
Zhang, J., Alpas, T. A. (1997). Transition Between Mild and Severe Wear in Aluminium Alloys, Acta Metall., Vol. 45, pp. 513-528. 


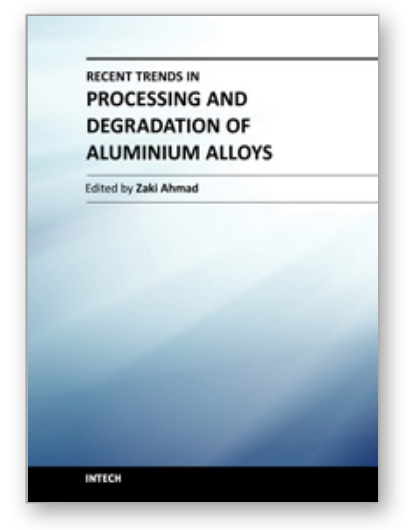

\section{Recent Trends in Processing and Degradation of Aluminium Alloys \\ Edited by Prof. Zaki Ahmad}

ISBN 978-953-307-734-5

Hard cover, 516 pages

Publisher InTech

Published online 21, November, 2011

Published in print edition November, 2011

In the recent decade a quantum leap has been made in production of aluminum alloys and new techniques of casting, forming, welding and surface modification have been evolved to improve the structural integrity of aluminum alloys. This book covers the essential need for the industrial and academic communities for update information. It would also be useful for entrepreneurs technocrats and all those interested in the production and the application of aluminum alloys and strategic structures. It would also help the instructors at senior and graduate level to support their text.

\section{How to reference}

In order to correctly reference this scholarly work, feel free to copy and paste the following:

Mariyam Jameelah Ghazali (2011). Effects of Dry Sliding Wear of Wrought Al-Alloys on Mechanical Mixed Layers (MML), Recent Trends in Processing and Degradation of Aluminium Alloys, Prof. Zaki Ahmad (Ed.), ISBN: 978-953-307-734-5, InTech, Available from: http://www.intechopen.com/books/recent-trends-inprocessing-and-degradation-of-aluminium-alloys/effects-of-dry-sliding-wear-of-wrought-al-alloys-onmechanical-mixed-layers-mml-

\section{INTECH}

open science | open minds

\section{InTech Europe}

University Campus STeP Ri Slavka Krautzeka 83/A 51000 Rijeka, Croatia Phone: +385 (51) 770447

Fax: +385 (51) 686166 www.intechopen.com

\section{InTech China}

Unit 405, Office Block, Hotel Equatorial Shanghai No.65, Yan An Road (West), Shanghai, 200040, China 中国上海市延安西路65号上海国际贵都大饭店办公楼405单元 Phone: +86-21-62489820

Fax: $+86-21-62489821$ 
(C) 2011 The Author(s). Licensee IntechOpen. This is an open access article distributed under the terms of the Creative Commons Attribution 3.0 License, which permits unrestricted use, distribution, and reproduction in any medium, provided the original work is properly cited. 